\title{
Pemanfaatan Sampah Rumah Tangga dan Pasar sebagai Upaya Peningkatan Kesejahteraan Keluarga
}

The Utilization of Household and Market Waste as an Effort to Enhancment Family Welfare

\author{
${ }^{1)}$ Yayat Sujatna, ${ }^{2 *}$ Widi Hastomo \\ ${ }^{1,2)}$ Program Studi Manajemen, Fakultas Ekonomi dan Bisnis \\ Institut Teknologi dan Bisnis Ahmad Dahlan \\ J1. Ciputat Raya No.77, Cireundeu, Kec. Ciputat Tim., Kota Tangerang Selatan, Banten 15419 \\ *email: widie.has@gmail.com
}

DOI:

10.30595/jppm.v5i1.5853

Histori Artikel:

Diajukan:

$08 / 11 / 2019$

Diterima:

$25 / 05 / 2021$

Diterbitkan:

22/07/2021

\section{ABSTRAK}

Jakarta memproduksi sekitar 7.700 ton sampah setiap harinya. Dari jumlah tersebut, sekitar 4.900 hingga 5.000 ton merupakan sampah organik. Rumah tangga dan pasar tradisional menjadi penghasil limbah yang produktif. Sampah organik yang dihasilkan dapat dikurangi dengan pemanfaatan menjadi pupuk organik cair(POC) yang bernilai jual tinggi. Pembentukan kelompok wirausaha mandiri bertujuan agar aktif membantu dalam mengurangi masalah sampah dengan dijadikan POC yang benilai jual tinggi serta peningkatan kesejahteraan keluarga. Mitra yang terlibat dalam kegiatan pengabdian kepada masyarakat (abdimas) ini yaitu kelompok ibu-ibu wirausaha mandiri warga RW 01 Tegal Alur Jakarta Barat. Metode yang digunakan yaitu Partisipatory Rural Apprasial (PRA), sebuah metode pada proses peningkatan partisipasi dan pemberdayaan masyarakat, dalam hal ini masyarakat ikut terlibat aktif pada seluruh kegiatan. Hasil dari program abdimas yaitu: 1)Meningkatnya pemahaman mitra tentang pembuatan POC dan kompos; 2)adanya hasil POC dan kompos; 3)meningkatkan pengetahuan dan kemampuan kelompok mitra dalam penerapan teknologi dan pengetahuan pada pengolahan sampah menjadi POC dan kompos; 4)mitra mampu memasarkan pupuk organik cair dan kompos baik secara offline maupun online; dan 5) meningkatnya pendapatan mitra dari hasil penjualan pupuk organik cair dan kompos; serta 6) meningkatnya kesadaran tentang dampak sampah yang timbul tanpa melalui proses daur ulang.

Kata kunci: Sampah; Pupuk Organik Cair

\begin{abstract}
Jakarta produces around 7,700 tons of waste every day, of which around 4,900 to 5,000 tons are organic waste. Households and traditional markets become productive waste producers, the organic waste produced can be reduced by using it as liquid organic fertilizer (POC). The formation of independent entrepreneurial groups aims to actively help reduce waste problems by turning them into POCs with high selling value and improving family welfare. Partners involved in the abdimas are groups of independent entrepreneurial women, residents of RW 01 Tegal Alur, West Jakarta. The method used is Participatory Rural Appraisal (PRA), a method in the process of increasing community participation and empowerment, in which the community is actively involved in all activities. The results of the abdimas program are 1) Increased understanding of partners about making POC and compost, 2) the results of POC and compost, 3) increase the knowledge and ability of partner groups in the application of technology and knowledge on processing waste into POC and compost 4) partners are able to market liquid organic fertilizers and compost both offline and online, 5) increased partner income from sales of fertilizers organic liquid and compost as well as increasing awareness about the impact of waste that arise without going through the recycling process.
\end{abstract}


Yayat Sujatna, Widi Hastomo

Pemanfaatan Sampah Rumah Tangga dan Pasar sebagai Upaya Peningkatan Kesejahteraan Keluarga

Keywords: Waste; Liquid Organic Fertilizer

\section{PENDAHULUAN}

Jakarta memproduksi sekitar 7.700 ton sampah setiap hari. Dari jumlah itu, sekitar 4.900 hingga 5.000 ton merupakan sampah organik. Kenyataan itu membuat Provinsi DKI Jakarta menempati posisi kedua daerah yang memproduksi sampah terbesar di perairan Indonesia. Sebagai warga DKI, berarti kita juga sebagai penyumbang atau ikut andil dalam permasalahan sampah tersebut (Anindiati, 2019).

Dari jaman Gubernur Ahok sampai saat sekarang Gubernur Anis Baswedan, kendala masalah sampah masih "menghantui" pemerintah DKI Jakarta, belum ditambah lagi dengan permasalahan dengan pemerintah Bekasi sebagi penyedia tempat pembuangan akhir di Bantar Gebang, sering kali terjadi kisruh, hal tersebut karena membawa dampak lingkungan untuk warga bekasi di sekitaran bantar gebang khususnya (Adytio, 2015).

Saat musim penghujan, pemerintah DKI Jakarta mendapatkan "paket kiriman" dari hulu seperti wilayah Depok, Bogor, dan sekitarnya yaitu sampah yang mencapai ratusan ton setiap harinya. Hal ini menjadikan daftar panjang permasalahan sampah di DKI Jakarta. Pihak pemerintah DKI setiap harinya harus mengeruk sampah mencapai 400 ton per harinya di bantaran sungai. Apabila sampah tersebut tidak segera dikeruk, maka dampak yang lebih besar akan segera terjadi yaitu permasalahan banjir, dan hal ini akan menjadikan permasalahan tersebut lebih komplek (Santoso, 2018).

Pihak pemerintah DKI Jakarta sudah sering mengedukasi warga di wilayah sekitaran sungai, misalnya saja sungai Ciliwung, untuk tidak membuang sampah ke sungai, tetapi sepertinya hanya isapan jempol belaka. Setelah diberikan edukasi hanya bertahan beberapa hari saja. Hal tersebut dibuktikan dengan menumpuknya sampah di sungai yang mencapai ratusan ton setiap hujan turun.

Di wilayah sekitaran Tegal Alur Kalideres terdapat 6 pasar tradisional yaitu, pasar Menceng, pasar Kamal, pasar Nangka, pasar Mirinda, pasar Cengkareng, dan pasar Laris. Pasar-pasar tradisional juga ikut menyumbang terjadinya penumpukan sampah tersebut. Warga sekitar pasar juga terkena dampak langsung dari sampah tersebut yang menjadi pemandangan setiap hari dan "mendapatkan aroma yang wangi" untuk setiap warga yang melewatinya, dan memberikan dampak lingkungan (Wharton, Vizcaino, Berardy, \& Opejin, 2021), kesehatan yang cukup signifikan (Blasius, Contrera, Maintinguer, \& Alves de Castro, 2020; Kanellopoulos, Verouti, Chrysochou, Koukoulakis, \& Bakeas, 2021). Padahal permasalahan seperti ini tidaklah sulit apabila masyarakar sadar akan dampak sampah tersebut dan pemanfaatan sampah tersebut mempunyai nilai jual yang tinggi (Chen, Zhang, \& Yuan, 2020; Dhanya, Mishra, Chandel, \& Verma, 2020).

Permasalahan sampah ini harus dimulai dari sekarang dari kita kemudian memberikan edukasi terhadap keluarga, dan masyarakat luas (Brotosusilo \& Handayani, 2020), edukasi terhadap keluarga yaitu dengan pemanfaatan limbah organik sisa pembuangan dari dapur seperti sampah sisa makanan, kulit buah, sisa sayur mayur, dan sejenisnya. Hal ini bisa membantu mengurangi sampah yang setiap harinya mencapai 7.700 ton tersebut dikonversi menjadi pupuk kompos dan cair organik. Pupuk tersebut memiliki nilai jual yang tinggi, bahkan dapat meningkatkan taraf kesejahteraan keluarga (Tounkara et al., 2020). Harga pupuk cair organik di pasaran dipatok kisaran Rp.15.000,- sampai dengan Rp. 17.000,- per liternya, sementara untuk pupuk kompos organik untuk media tanam bisa mencapai Rp. 22.000,- sampai dengan Rp. 28.000 ,- per 5 kg-nya (perbandingan pupuk organik dan tanah subur 1:1).

Proses pembuatan pupuk organik tersebut tergolong cukup mudah dan tidak membutuhkan biaya yang mahal. Hasil proses pembuatan pupuk organik tersebut bisa dijual ke masyarakat sekitar, bisa dijual ke pedagang tanaman-tanaman yang banyak di pinggir jalan, atau bisa melalui media online (ecommerce) (Harto, Pratiwi, Utomo, \& 
Rahmawati, 2019), (Werdani, Kurniawati, Sukoco, Windriya, \& Iskandar, 2020). Target dari edukasi pemanfaatan sampah pasar dan rumah tangga menjadi pupuk organik sebagai upaya peningkatan kesejahteraan keluarga (Amin \& Subri, 2018) diawali dari kelompok wirausaha mandiri Ibu-ibu rumah tangga (Muryani, Widiarti, \& Savitri, 2020) di RW 01 Kelurahan Tegal Alur. Hasilnya diharapkan dapat menambah kesejahteraan keluarga secara finansial ibu-ibu rumah tangga tersebut, ramah lingkungan dengan membuat hijau lahan pekarang dengan ditanami tanaman hias atau pohon buah (Rahajuni, Badriah, Tini, \& Lestari, 2020), dan yang paling utama yaitu mengurangi sampah.

Salah satu manfaat pupuk organik cair yaitu dapat menggantikan pupuk anorganik untuk proses pertumbuhan dan pembuahan serta menjadikan sampah berkurang, serta dapat menggemburkan tanah atau menyuburkan kembali struktur tanah. Kompos banyak mengandung mikroorganisme, dengan ditambahkannya kompos di dalam tanah memacu berkembangnya mikroorganisme dalam tanah, gas $\mathrm{CO}_{2}$ yang dihasilkan mikroorganisme tanah akan dipergunakan untuk fotosintesis tanaman dan menghasilkan hormon-hormon pertumbuhan (Badan Litbang Pertanian, 2011).

Berdasarkan permasalahan-permasalah yang dihadapi oleh Pemerintah DKI khususnya dan warga sekitaran pasar tradisional di wilayah RW 01 Tegal Alur dapat diidentifikasi dan dirumuskan sebagai berikut:

1. Sampah pasar tradisonal menggunung. Hal ini dikarenakan pengelolaan sampah pasar masih tradisional, yaitu sampah diambil oleh truk dinas kebersihan dan kemudian dibuang d ipembuangan akhir di Bantar Gebang. Para pedagang merasa sudah melakukan kewajibannya yaitu dengan membayar biaya kebersihan setiap harinya, dan kebanyakan dari mereka tidak peduli lagi mengenai permasalahan dari sampah tersebut, dimana sampah tersebut terakhir akan dibuang, dan siapa yang melakukannya.

2. Rumah tangga menjadi penghasil sampah yang produktif. Rumah tangga disebut menjadi penghasil sampah yang produktif karena setiap hari rumah tangga menghasilkan limbah atau sampah dari sisa proses memasak dan sisa makanan. Bisa dibayangkan berapa ton sampah perharinya yang dihasilkan oleh setiap rumah tangga. Dan itu menjadi penyumbang permasalahan yang saat ini terjadi di DKI Jakarta, khususnya di wilayah RW 01 Tegal Alur

3. Kurangnya informasi tentang dampak sampah. Warga di RW 01 Tegal Alur kurang paham dampak yang dirasakan langsung dan tidak langsung dari masalah sampah tersebut. Dampak yang dirasakan langsung yaitu di wilayah tersebut menjadi kumuh, tercium aroma yang tidak sedap, banyak lalat dan bakteri yang merugikan di sampah tersebut. Sampah-sampah plastik kresek, plastik bekas air mineral dan lain-lain, bila terisi air hujan akan menjadi sarang nyamuk dan dapat berkembang biak. Limbah yang masuk kedalam tanah akan mencemari air, dan air tersebut tidak dapat dimanfaatkan untuk kegiatan sehari-hari, karena sudah tidak layak. Sehingga air tanah dan aliran air sungai tercemar. Sementara itu untuk dampak yang tidak langsung yaitu bagi kesehatan warga, khususnya bagi anakanak dan balita. Masalah ini tidak sepenuhnya menjadi tanggung jawab pemerintah DKI Jakarta, tetapi juga menjadi tanggung jawab warga RW 01 Tegal Alur.

4. Habit atau kebiasaaan warga yang sulit dirubah. Di wilayah Tegal Alur, apabila warga membuang sampah dari rumah tangga harus mengeluarkan biaya untuk pembuangan sampah tersebut. Hal ini sudah wajar tentunya karena biaya yang dikeluarkan tersebut untuk pekerja yang mengangkut sampah setiap harinya. Banyak warga sekitaran yang enggan mengeluarkan biaya tersebut dengan dalih biaya mahal, hidup di Jakarta sudah sulit, penghasilan pas-pasan dan banyak alasan yang lainnya. Alhasil, warga tersebut membuang sampah di sembarang tempat, dan munculah permasalahan sampah.

5. Pada pengolahan sampah mampu menjadi pupuk organik cair dan kompos mempunyai nilai tinggi. Warga di RW 01 belum mengerti jika sampah rumah tangga 
dan sampah dari pasar tradisional yang dihasilkan setiap harinya apabila diolah menjadi pupuk organik cair dan kompos maka mempunyai nilai jual tinggi. Harga pupuk cair organik 1 liter yang dihasilkan dari pengolahan limbah sampah tersebut lebih mahal dibandingkan air mineral kemasan. Tidak hanya itu saja yang dapat dihasilkan dari sampah rumah tangga, hasil akhirnya juga bisa menjadi pupuk kompos organik untuk media tanam, dan ini juga mempunyai nilai jual tinggi, untuk kompos kemasan $5 \mathrm{~kg}$, bisa mencapai Rp.22.000,- sampai dengan Rp.28.000,- di pasaran.

Tujuan dilaksanakannya pengabdian masyarakat ini adalah sebagai berikut:

1) Membentuk kelompok wirausaha mandiri dalam memproduksi pengolahan sampah rumah tangga dan pasar tradisional menjadi pupuk organik yang benilai jual tinggi.

2) Menciptakan pengetahuan dan teknik pengolahan sampah rumah tangga dan pasar tradisional menjadi pupuk organik cair dan kompos.

3) Meningkatkan pengetahuan dan kemampuan kelompok mitra dalam penerapan teknologi dan pengetahuan pada pengolahan sampah menjadi pupuk organik cair dan kompos;

4) Meningkatkan nilai yang tinggi dari sampah rumah tangga dan pasar tradisional melalui proses komposer.

5) Meningkatkan kesejahteraan kelompok Ibu-ibu wirausaha mandiri warga RW 01 Tegal Alur

Adapun manfaat yang diperoleh dari pelaksanaan pengabdian masyarakat ini adalah sebagai berikut:

1) Meningkatkan kemampuan memproduksi pengolahan sampah rumah tangga dan pasar tradisional menjadi pupuk organik yang mempunyai nilai tinggi.

2) Mengembangkan teknik pengolahan dan pengetahuan sampah rumah tangga dan pasar tradisional menjadi pupuk organik cair dan kompos.

3) Mengembangkan usaha menjadi lebih profesional sebagai sentra pengolahan sampah menjadi pupuk organik cair dan kompos.

4) Meningkatkan taraf kesejahteraan keluarga melalui pendapatan usaha penjualan pupuk cair organik dan kompos. Jika dilakukan secara tekun dan kontinu dapat dijadikan sebuah pekerjaan, guna mendukung program pengentasan pengangguran (Sujatna \& Istimal, 2018).

Khalayak sasaran atau mitra pengabdian masyarakat ini adalah kelompok wirausaha mandiri Ibu-Ibu di RW 01 Tegal Alur, Kalideres Jakarta Barat.

\section{METODE}

Metode yang digunakan untuk mengatasi masalah yang dihadapi oleh khalayak sasaran (mitra) adalah dengan pendekatan Partisipatory Rural Apprasial (PRA), menggunakan sebuah metode pada proses peningkatan partisipasi dan pemberdayaan masyarakat, dalam hal ini masyarakat ikut terlibat aktif pada seluruh kegiatan.

Tahapan-tahapan pelaksanaan kegiatan pengabdian terdiri dari penyuluhan, pelatihan dan praktek langsung serta evaluasi. Tahapan tersebut dapat digambarkan sebagaimana Gambar 1.

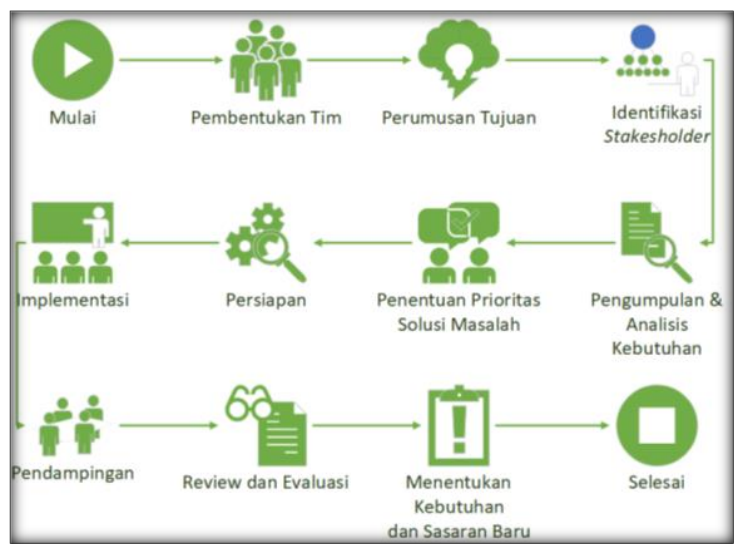

Gambar 1. Metode dan Pelaksanaan Pengabdian Masyarakat

1. Tahapan awal dalam pengabdian masyarakat ini yaitu pembentukan Tim, kerjasama antara dosen Institut Teknologi dan Bisnis Ahmad Dahlan. 
2. Perumusan tujuan yaitu program pengabdian masyarakat yang diadakan oleh Institut Teknologi Bisnis Ahmad Dahlan adalah salah satu Tridharma perguruan tinggi.

3. Stakeholder dalam pengabdian masyarakat ini yaitu; (a). Internal stakeholder $\rightarrow$ Institut Teknologi dan Bisnis Ahmad Dahlan, LP3M dan Dosen. (b). Eksternal stakeholder $\rightarrow$ RT 04 dan RW 01, pihak dari Kelurahan Tegal Alur dan Kecamatan Kalideres, Wirausaha mandiri Ibu-Ibu warga RW 01 Tegal Alur.

4. Pengumpulan dan analisis kebutuhan $\rightarrow$ (a). Sampah Pasar Tradisonal menggunung, hal ini dikarenakan pengelolaan sampah pasar masih tradisional, yaitu sampah diambil oleh truk dinas kebersihan dan kemudian dibuang dipembuangan akhir di bantar gebang. (b). Rumah tangga menjadi penghasil sampah yang produktif karena setiap hari rumah tangga menghasilkan limbah atau sampah dari sisa proses memasak dan sisa makanan. (c). Habit atau kebiasaaan warga yang sulit dirubah, banyak warga sekitaran yang enggan mengeluarkan biaya untuk proses pembuangan sampah dengan dalih biaya mahal, hidup di jakarta sudah sulit, penghasilan pas-pasan dan banyak alasan yang lainnya. Alhasil warga tersebut membuang sampah disembarang tempat, dan munculah permasalahan sampah. (d). Warga di RW 01 belum memahami sampah rumah tangga dan sampah dari pasar tradisional yang dihasilkan setiap harinya apabila diolah menjadi pupuk organik cair dan kompos maka mempunyai nilai jual tinggi. (e). Dalam proses pembuatan pupuk organik cair agar dapat berdampak secara signifikan, maka dengan proses masal, hal ini mampu memberikan dampak yang nyata pada pengurangan limbah dan memberikan habit yang lebih baik bagi masyarakat wilayah RW 01 Tegal Alur. (f). Dalam hal ini
Pemerintah memberikan dukungan yang nyata melalui program Go Organi yang dicanangkan dari tahun 20015. (g). Industri pupuk organik cair di Indonesia harus didukung sepenuhnya oleh para stakeholder agar memberikan manfaat yang nyata. Hal ini agar dapat menutup kebutuhan pupuk organik yang selama ini masih belum terpenuhi karena masih dalam skala yang kecil.

5. Penentuan Prioritas Solusi Masalah $\rightarrow$ (a). Membentuk kelompok wirausaha mandiri dalam memproduksi pengolahan sampah rumah tangga dan pasar tradisional menjadi pupuk organik yang benilai jual tinggi. (b). Peningkatan pengetahuan dan teknik pengolahan sampah rumah tangga dan pasar tradisional menjadi pupuk organik cair dan kompos. (c). Meningkatkan pengetahuan dan kemampuan kelompok mitra dalam penerapan teknologi dan pengetahuan pada pengolahan sampah menjadi pupuk organik cair dan kompos; (d). Meningkatkan nilai yang tinggi dari sampah rumah tangga dan pasar tradisional melalui proses komposer. (e). Meningkatkan kesejahteraan kelompok Ibu-ibu wirausaha mandiri warga RW 01 Tegal Alur.

6. Persiapan $\rightarrow$ Hal yang perlu dipersiapkan dalam pengabdian masyarakat.

Kegiatan evaluasi pengabdian masyarakat dilakukan untuk mengetahui efektifitas atau keberhasilan kegiatan pengabdian masyarakat dilakukan. Kegiatan ini dilakukan setelah kegiatan pengabdian selesai dilaksanakan. Keberhasilan atau efektivitas kegiatan dapat dilihat dari capaiancapaian kegiatan berdasarkan indikatorindikator tertentu. Adapun indikator capaian dalam kegiatan pengabdian masyarakat ini ditampilkan pada tabel 1 . 
Yayat Sujatna, Widi Hastomo

Pemanfaatan Sampah Rumah Tangga dan Pasar sebagai Upaya Peningkatan Kesejahteraan Keluarga

Tabel 1. Tabel Evaluasi Kegiatan

\begin{tabular}{clll}
\hline No. & \multicolumn{1}{c}{ Indikator Keberhasilan } & Sumber Data & \multicolumn{1}{c}{ Instrumen } \\
\hline 1 & $\begin{array}{l}\text { Meningkatnya pemahaman mitra tentang } \\
\text { pembuatan pupuk organik cair dan kompos }\end{array}$ & Primer & $\begin{array}{l}\text { Persepsi mitra melalui } \\
\text { pertanyaan kuesioner } \\
\text { dan/atau wawancara }\end{array}$ \\
\hline 2 & $\begin{array}{l}\text { Mitra mampu membuat pupuk organik cair } \\
\text { dan kompos }\end{array}$ & Primer & Pengamatan langsung \\
\hline 3 & $\begin{array}{l}\text { Adanya hasil pupuk organik cair dan } \\
\text { kompos }\end{array}$ & Primer & Pengamatan langsung \\
\hline 4 & $\begin{array}{l}\text { Mitra mampu memasarkan pupuk organik } \\
\text { cair dan kompos baik offline maupun } \text { online. }\end{array}$ & Primer & $\begin{array}{l}\text { Pangamatan langsung, } \\
\text { media sosial }\end{array}$ \\
\hline 5 & $\begin{array}{l}\text { Meningkatnya pendapatan mitra dari hasil } \\
\text { pupuk organik cair dan kompos }\end{array}$ & Sekunder & $\begin{array}{l}\text { Laporan } \\
\text { usaha mitra }\end{array}$ \\
\hline
\end{tabular}

\section{HASIL DAN PEMBAHASAN}

Alat yang digunakan dalam pembuatan pupuk organik cair yaitu, tong yang sudah didesain seperti pada gambar 2, EM4, semprotran, dan limbah organik.

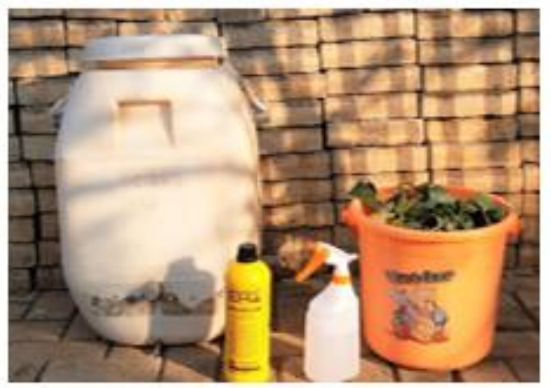

Gambar 2. Bahan POC

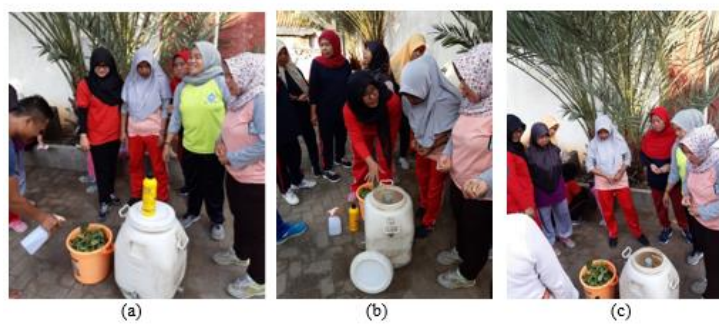

Gambar 3. Proses pembuatan POC (a),

Edukasi terhadap mitra (b-c)

Proses pembuatan pupuk cair organik dengan bahan dasar sampah rumah tangga dan sampah hasil dari pasar tradisional cukup sederhana. Bahan organik tersebut seperti kulit pisang, kulit singkong, dan sisa sayur mayur, sisa makanan yang tidak habis, apabila terdapat nasi basi, nasi tersebut harus dicuci terlebih dahulu. Apabila masih tercampur degan sampah anorganik, pilah terlebih dahulu sampah rumah tangga dan pasar tradisional yang organik, kemudian limbah organik tersebut dicincang agar lebih cepat dalam proses pembusukan. Proses selanjutnya yaitu disemprot dengan merata menggunakan cairan EM4. Setelah disemprot dengan merata, limbah sampah tersebut dimasukkan ke tong. Apabila esok hari ingin menambah lagi, prosesnya masih sama yaitu limbah organiknya dicincang kemudian disemprot dengan EM4 lalu dimasukkan ke dalam tong.

Antusiasme warga cukup bersemangat, karena selama ini belum mengetahui nilai lebih dari sampah yang sudah tidak bisa digunakan, apabila ingin mendapatkan nilai lebih dari hasil pupuk organik cair, masyarakat bisa mengambil sampah organik di pasar-pasar tradisional disekitaran Tegal Alur. Hal tesebut bisa menambah pendapatan dari Ibu-Ibu rumah tangga dan kesejahteranaan meningkat.

Kegiatan evaluasi dilakukan agar mitra memahami dan sesuai dengan tujuan program abdimas ini;

1. Meningkatnya pemahaman mitra tentang pembuatan pupuk organik cair dan kompos. Hasil dari evaluasi ini yaitu mitra mampu memahami proses pembuatan POC yang sangat sederhana. Rumah tangga mampu mendaur ulang limbah secara mandiri. Hasil pre-test kuesioner menunjukkan tingkat pemahaman mitra berkisar di 50\%, untuk hasil post-test, pemahaman mitra meningkat menjadi $90 \%$.

2. Mitra mampu membuat pupuk organik cair dan kompos. Hasil evaluasi yaitu mitra 
memahami alur atau langkah-langkah pembuatan POC yang sederhana.

3. Adanya hasil pupuk organik cair dan kompos. Hasil evaluasi yaitu setelah melalui proses pembuatan, mitra mampu mengemas POC kemasan botol $100 \mathrm{ml}$ dan kompos $5 \mathrm{~kg} / \mathrm{bag}$ siap jual. Kedepannya produk tidak perlu dikemas, untuk penjualan di sekitaran wilayah Tegal Alur dengan cara pembeli membawa kemasan isi ulang, agar konsep 3R (reuse, reduce dan recycle) tetap terjaga.

4. Mitra mampu memasarkan pupuk organik cair dan kompos baik secara offline maupun online. Hasil evaluasi yaitu mitra berhasil memasarkan produk POC dan bekerjasama dengan UMKM di lingkungan Tegal Alur Jakarta Barat. Rasio penjualan $80 \%$ offline dan $20 \%$ online.

5. Meningkatnya pendapatan mitra dari hasil pupuk organik cair dan kompos. Hasil evaluasi yaitu mitra mampu menjual POC rerata dalam 1 bulan 70 botol $(100 \mathrm{ml}) \mathrm{x}$ Rp.10.000,- = Rp. 700.000,- sedangkan penjualan kompos rerata dalam 1 bulan yaitu 40 bag $(5 \mathrm{~kg}) \times \mathrm{Rp} .10 .000,-=\mathrm{Rp}$. 400.000,- dalam penjualan ini masih didominasi Word of Mouth secara offline. Harapan kedepannya yaitu mampu memaksimalkan media marketplace dan social media (Yunita \& Purwanto, 2020).

\section{SIMPULAN}

Dari hasil kegiatan pengabdian masyarakat ini dapat disimpulkan bahwa dari kegiatan ini berhasil terbentuk wirausaha mandiri yang mampu memproduksi limbah rumah tangga dan pasar menjadi POC dan kompos. Tercipta pemahaman proses pembuatan POC dengan bahan dasar limbah rumah tangga dan pasar. Pengetahuan dan kemampuan kelompok mitra dalam penerapan teknologi untuk mengolah limbah mengalami peningkatan. Mitra mampu menciptakan peluang pada limbah menjadi POC yang cukup bernilai tinggi. Hasil dari penjualan POC dan kompos dapat meningkatkan kesejahteraan keluarga mitra.

Capaian lain yang tidak kalah penting yaitu mampu merubah habit atau kebiasaan sehari-hari dengan cara mengedukasi dan memberikan fakta bahwa masalah sampah merupakan masalah yang cukup serius, apabila tidak segera ditanggulangi maka akan berdampak cukup luas.

\section{DAFTAR PUSTAKA}

Adytio, D. (2015). Jakarta vs Bekasi, Begini Kisruh Sampah Bantargebang dari Masa ke Masa. DetikNews. Retrieved from https://news.detik.com/berita/d3060998/jakarta-vs-bekasi-begini-kisruhsampah-bantargebang-dari-masa-ke-masa

Amin, M., \& Subri, M. (2018). Pelatihan Pembuatan Makanan Ringan Ekstrudat Jagung Guna Meningkatkan Pendapatan Masyarakat. JPPM (Jurnal Pengabdian Dan Pemberdayaan Masyarakat), 2(1), 43.

https://doi.org/10.30595/jppm.v2i1.1639

Anindiati. (2019). Jakarta Hasilkan 7.700 Ton Sampah per Hari. Retrieved August 30, 2020, from Kompas.com website: https://sains.kompas.com/read/2019/11/0 1/190700323/jakarta-hasilkan-7.700-tonsampah-per-hari?page=all

Badan Litbang Pertanian. (2011). Pupuk Organik dari Limbah Organik Sampah Rumah Tangga. Agroinovasi, (3417), 211. Retrieved from http://www.litbang.pertanian.go.id/downl oad/one/184/file/Pupuk-Organik-dariLimbah.pdf

Blasius, J. P., Contrera, R. C., Maintinguer, S. I., \& Alves de Castro, M. C. A. (2020). Effects of temperature, proportion and organic loading rate on the performance of anaerobic digestion of food waste. Biotechnology Reports, 27, e00503. https://doi.org/10.1016/j.btre.2020.e0050 3

Brotosusilo, A., \& Handayani, D. (2020). Dataset on waste management behaviors of urban citizens in large cities of Indonesia. Data in Brief, 32. https://doi.org/10.1016/j.dib.2020.10605 3

Chen, T., Zhang, S., \& Yuan, Z. (2020). 
Adoption of solid organic waste composting products: A critical review. Journal of Cleaner Production, 272, 122712.

https://doi.org/10.1016/j.jclepro.2020.12 2712

Dhanya, B. S., Mishra, A., Chandel, A. K., \& Verma, M. L. (2020). Development of sustainable approaches for converting the organic waste to bioenergy. Science of the Total Environment, 723, 138109. https://doi.org/10.1016/j.scitotenv.2020.1 38109

Harto, D., Pratiwi, S. R., Utomo, M. N., \& Rahmawati, M. (2019). Penerapan Internet Marketing Dalam Meningkatkan Pendapatan Pada UMKM. JPPM (Jurnal Pengabdian Dan Pemberdayaan Masyarakat), 3(1), 39. https://doi.org/10.30595/jppm.v3i1.3033

Kanellopoulos, P. G., Verouti, E., Chrysochou, E., Koukoulakis, K., \& Bakeas, E. (2021). Primary and secondary organic aerosol in an urban/industrial site: Sources, health implications and the role of plastic enriched waste burning. Journal of Environmental Sciences (China), $\quad 99, \quad 222-238$. https://doi.org/10.1016/j.jes.2020.06.012

Muryani, E., Widiarti, I. W., \& Savitri, N. D. (2020). Pembentukan Komunitas Pengelola Sampah Terpadu Berbasis Masyarakat. JPPM (Jurnal Pengabdian Dan Pemberdayaan Masyarakat), 4(1), 117. https://doi.org/10.30595/jppm.v0i0.5647

Rahajuni, D., Badriah, L. S., Tini, E. W., \& Lestari, S. (2020). Mewujudkan Kota Tanpa Kumuh Melalui Sistem Kebun Bersama. JPPM (Jurnal Pengabdian Dan Pemberdayaan Masyarakat), 4(1).

Santoso, B. (2018). Miris, Sampah Sungai di Jakarta Capai 400 Ton Setiap Hari. Suara.Com. Retrieved from https://www.suara.com/news/2018/09/18/ 113846/miris-sampah-sungai-di-jakartacapai-400-ton-setiap-hari

Sujatna, Y., \& Istimal, I. (2018). Pengentasan
Pengangguran Bagi Pemuda Di Desa Cigudeg Melalui Kegiatan Budidaya Ikan Lele. JPPM (Jurnal Pengabdian Dan Pemberdayaan Masyarakat), 2(2).

Tounkara, A., Clermont-Dauphin, C., Affholder, F., Ndiaye, S., Masse, D., \& Cournac, L. (2020). Inorganic fertilizer use efficiency of millet crop increased with organic fertilizer application in rainfed agriculture on smallholdings in central Senegal. Agriculture, Ecosystems and Environment, 294(February). https://doi.org/10.1016/j.agee.2020.1068 78

Werdani, R. E., Kurniawati, N. I., Sukoco, J. B., Windriya, A., \& Iskandar, D. (2020). Pelatihan Pemasaran Produk Homemade Melalui Sosial Media. JPPM (Jurnal Pengabdian Dan Pemberdayaan Masyarakat), $\quad 4(1), \quad 1$. https://doi.org/10.30595/jppm.v4i1.4655

Wharton, C., Vizcaino, M., Berardy, A., \& Opejin, A. (2021). Waste watchers: A food waste reduction intervention among households in Arizona. Resources, Conservation and Recycling, 164(August 2020), 105109. https://doi.org/10.1016/j.resconrec.2020. 105109

Yunita, A., \& Purwanto, H. (2020). Peningkatan Pemasaran Produk Kerajinan Bambu di Dusun Sanggrahan I, Desa Muntuk, Dlingo, Bantul. JPPM (Jurnal Pengabdian Dan Pemberdayaan Masyarakat), $\quad 4(1), \quad 149$. https://doi.org/10.30595/jppm.v0i0.4603 